\title{
Assisted Birth Delivery In Ghana: Evidence From Ghana Demographic And Health Survey 1988 - 2014
}

Kenneth Fosu Oteng ( $\square$ otengkenneth24@gmail.com )

Ghana Health Service https://orcid.org/0000-0003-2772-3295

Richard Aboagye-Mensah

Ghana Education Service

Kwamena Sekyi Dickson

Department Of Population And Health

Research article

Keywords: assisted birth delivery, child birth, delivery

Posted Date: November 19th, 2020

DOI: https://doi.org/10.21203/rs.3.rs-111114/v1

License: (1) This work is licensed under a Creative Commons Attribution 4.0 International License.

Read Full License 


\section{Abstract}

Background: Assistance during birth delivery is an essential reproductive care given to women during pregnancy. Even with the best possible antenatal care, any delivery can become a complicated one; therefore, skilled assistance is essential to safe delivery care. Proven health care interventions such as skilled assistance during childbirth can prevent or manage these complications.

Methods: The study used secondary data from all the six rounds of the Ghana Demographic and Health Survey (GDHS). Bivariate, multivariate and binary logistic regression models were applied to examine the association between some background characteristics and assisted birth delivery.

Results: The results showed that birth delivery is generally assisted by Nurses/Midwives over the period under review. The proportion of women who were not assisted during delivery declined over the period. Similarly, there was a decline in the percentage of women who were assisted by traditional birth attendants. In addition, it was observed that older women were more likely to be assisted by doctors during delivery as compared with younger women. Women with secondary education were more likely to utilize the services of nurses/midwives during delivery compared with those with no education. Women from the rural areas were more likely to receive delivery assistance from Traditional Birth Attendants compared with those from urban areas.

Conclusion: These findings heighten that future successful interventions for skilled birth attendants should prioritise the identified groups who were more likely to utilize the services of TBAs.

\section{Background}

Labour and delivery are the shortest and most critical period of pregnancy and childbirth continuum because most maternal deaths arise from complications during delivery. Even with the best possible antenatal care, any delivery can become a complicated one; therefore, skilled assistance is essential to safe delivery care [1]. Proven health care interventions such as skilled assistance during childbirth can prevent or manage these complications [2].

Maternal health refers to the health of women during pre-conception, pregnancy, childbirth and postpartum period. It includes education, health promotion, screening, family planning, nutrition, breastfeeding, maternal age, frequency and spacing of birth in order to reduce maternal morbidity and mortality [3].

In the continuum of maternal health care, skilled attendant at delivery is an important milestone required to achieve optimum maternal and child health. This element of care is expected to be provided as part of the continuum of health care in order to impact optimum benefit. The provision of the skilled attendant in a comprehensive and continuum pattern of care during childbirth has been argued to reduce maternal and neonatal death [4]. 
Child delivery in the past was assisted by mother-in-law, mother, and aunt or sister-in-law before the emergence of conventional medicine; however, where there were complications, Traditional Birth Attendants (TBAs) were invited to help [5]. A TBA is defined as a person who has acquired the skills of delivering babies either through apprenticeship to other TBAs or self-acquired skills to assist the expectant mother during childbirth [6]. As of the year 2012, that the number of TBAs in developing countries is not known, meanwhile, conventional estimates suggest that there would be between 180 million non-skilled birth attendants in sub-Saharan Africa [7].

In the management of pregnancy and child delivery, TBAs frequently use their bare hands to examine the vagina and apply herbal medicines to the vulva or vagina to ensure the health of the growing fetus and safe delivery. However, some of these practices might cause genital infections including pelvic sepsis [8] which is one of the major causes of infertility, menstrual disorders and ectopic pregnancies [9]. Moreover, TBAs are responsible for management of family planning, getting opposite sex for a woman who is giving birth to the same sex, managing temporary impotence and infertility using traditional remedies [6].

Most obstetric complications that occur around the time of delivery cannot be predicted. Therefore, it is important that all pregnant women have access to the skilled attendant. Skilled attendance at delivery is advocated as the "single most important factor in preventing maternal deaths" [10]. The proportion of births attended to by skilled health personnel has been embedded in the Sustainable Development Goal (SDG) 3 target 3.1 - reducing the global maternal mortality ratio to less than 70 per 100,000 [11].

Strategies to improve maternal health are constrained by inadequate skilled birth attendants and underfunding of maternal and child health [12]. Other factors obstructing progress toward improving maternal health include barriers to accessing healthcare, inadequate essential supplies, lack of emergency transport systems and poor referral services [13].

The risk of women dying from pregnancy-related causes during their lifetime is 1 in 40 in Africa as compared with 1 in 3,300 in Europe and 1 in 190 globally [14]. An insignificant number of the deaths (1\%) occur in the developed countries as a result of availability and accessibility of quality of care by pregnant women in the developed countries. This quality care includes skilled attendant at the delivery point [12].

The government of Ghana introduced a maternal care exemption fee policy in 2007 to eliminate the financial burden of access to maternal health services [15], enhance easy access to facilities, train more midwives, upgrade health assistant schools into midwifery schools, offer Community-based Health Planning and Services (CHPS) Program and train Community Health Officers (CHOs) as midwives to address the gap in skilled attendance $[16,17,18,13,12]$.

\section{Methods}

\section{Sources of Data}


This study used six datasets from Ghana Demographic and Health Survey (GDHS) conducted in 1988, $1993,1998,2003,2008$ and 2014 . The GDHS is a nationwide survey that is carried out every five years since it began. The survey gathers information on fertility, family planning, infant and child mortality, maternal and child health as well as nutrition. The information on maternal and child health include Antenatal Care and delivery care. This provides adequate data for monitoring the population and health situation in Ghana.

\section{Description and definition of Variables}

\section{Dependent Variable}

The study equated assisted delivery at birth to an outcome variable. This variable was generated from the response to the question that assessed "the type of person that assisted women in the delivery of the child". Responses were grouped as women who were assisted by a doctor, nurse/ midwife, community health officer, traditional birth attendants, relatives, friends, no one, and other.

\section{Independent Variables}

The study made use of nine independent variables, these are; maternal age, educational level, residence, marital status, wealth status, parity, occupation, ethnicity and region. Maternal age was categorized into 15-19, 20-24, 25-29, 30-34, 35-39, 40-44 and 45-49. The educational level was classified into women having No education, Primary education, Secondary education and Higher education. The type of residence was coded as Rural or Urban settlement.

Marital status was recoded into Married, never married, widowed, divorced and Cohabitation. The wealth status was grouped in five (5) quintiles. These are Poorest, Poorer, Middle, Richer, and Richest. Parity was coded from a question that assessed the number of children a woman had ever given birth to prior to the current pregnancy. Responses were grouped into Null birth, One birth, Two births, Three births and Four or more births. The occupation was grouped into Not working, Managerial, Clerical, sales, agricultural, services and Manual workers. In addition, Ethnicity was classified as Akan (Asante, Akwapim, Fante and other), Ga-Adangbe, Ewe, Guan, Mole-Dagbani, Grussi, Gruma, Mande, and Others. The recoding of variables was done based on the literature reviewed.

\section{Data Analysis}

The data was analyzed using STATA version 13 with the use of both inferential and descriptive statistics. Some variables were recoded based on literature to suit the objectives of this study after which tables and graph were used for the presentation of the results. The results were weighted with the available sample weight factor (v005) within the GDHS data. Univariate, bivariate, multivariate and binary logistic regression analysis were employed.

Binary logistic was used to assess the effect of the independent variables on a specific outcome variable. It is based on the assumption that the outcome variable is dichotomous in nature and also has no outliers. The outcome variables are captured in dichotomous variables and so helped to explain their associations with independent variables. 


\section{Results}

\section{Background Characteristics Of Respondents}

This section covers the socio-demographics of the respondents namely; age, residence, region, education, wealth status, marital status, occupation, parity and ethnicity as captured in the GDHS. The age of the respondents ranges from 15-49 years. The mean age of the respondents was 27 years in 1988 and 30 years in 2014. Table 3 shows that respondents were mainly aged $25-29$ years. For example, in 1988, about 27 percent of the women were in the 25-29 age group and about 24 percent in 2014 .

The majority of the respondents were from the rural areas, thus, about 72 percent in 1988 and a little above half (54 percent) in 2014. The level of education of the respondents varied. For instance, the majority of respondents had primary education in 1988 and 1993 whereas the highest proportions had secondary education in 1998, 2008 and 2014. In 2003, the highest proportion (39 percent) had no education.

With regards to the wealth status of the respondents, the proportion ranges from about 14 percent to about 25 percent (see Table 1). For example, in 2008, about 15 percent were in the richest wealth quintile while about 23 percent were in the poorest wealth quintile. The majority of respondents were married in all the years under review, even though there were variations in the percentages. For example, about 82 percent in 1988 and about 62 percent in 2014. There was sharp increment among those in cohabitation from 6 percent in 1988 to 22 percent in 2014. The highest proportion of respondents were from the Ashanti Region with the lowest proportion in the Upper West Region.

For instance, in 2014, about 18 percent were from the Ashanti Region while 3 percent were from the Upper West Region. Respondents from the Akan ethnic group dominated in all the years under review. For example, 51 percent were from the Akan ethnic group in 1988 and 47 percent in 2014. The occupational status under the years of review was mixed. For instance, in 1988, about 46 percent of the sampled women were not working whereas, in 1998, 2008 and 2014, women who were into sales had the highest proportions, thus, 34 percent, 36 percent and 38 percent respectively. Table 1 indicates that the highest

proportion of the respondents had four births or more. For example, about 49 percent of the respondents had four birth or more in 1988 and about 39 percent of the respondents had four births or more in 2014 . 
Table 1

Background Characteristics

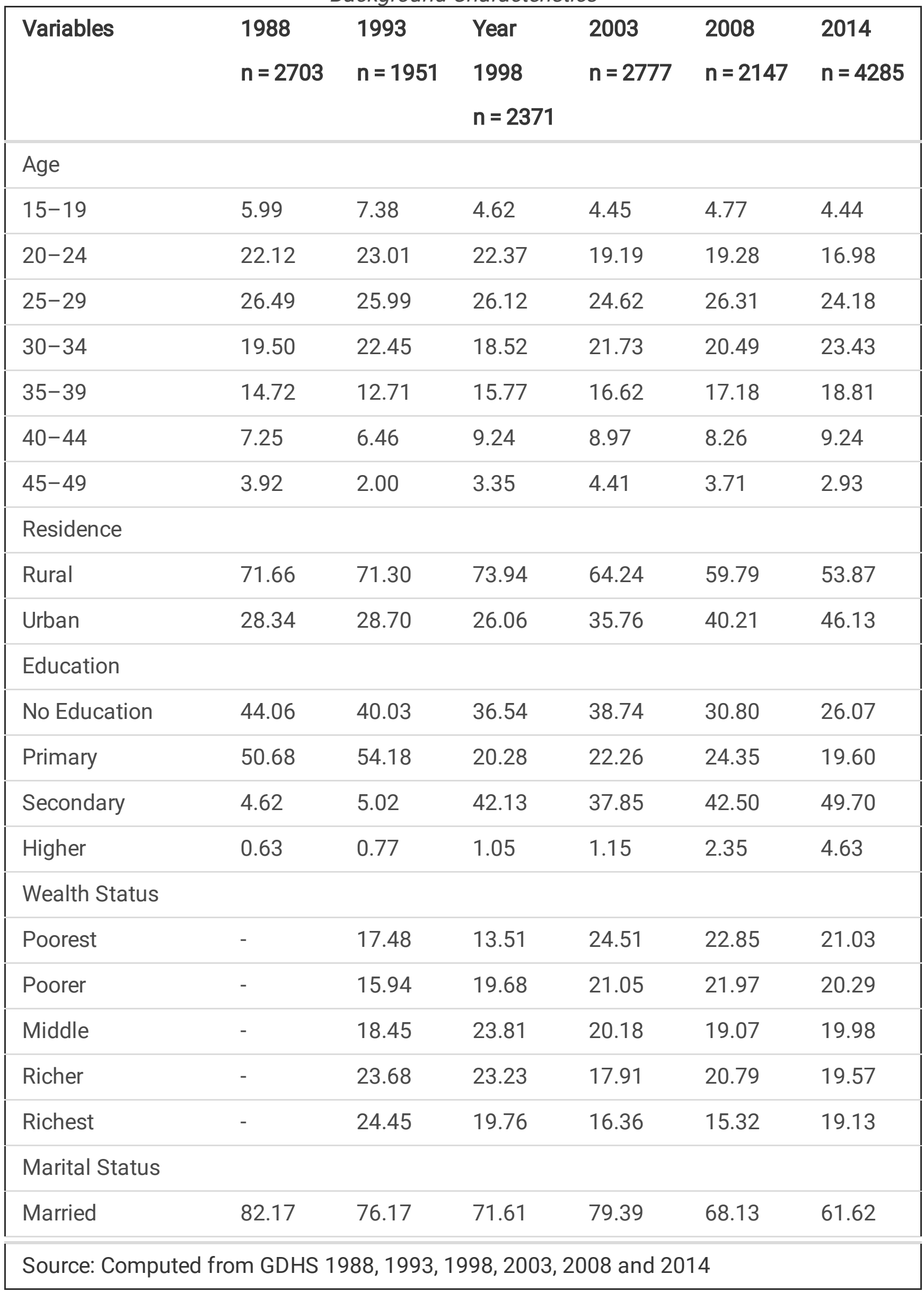




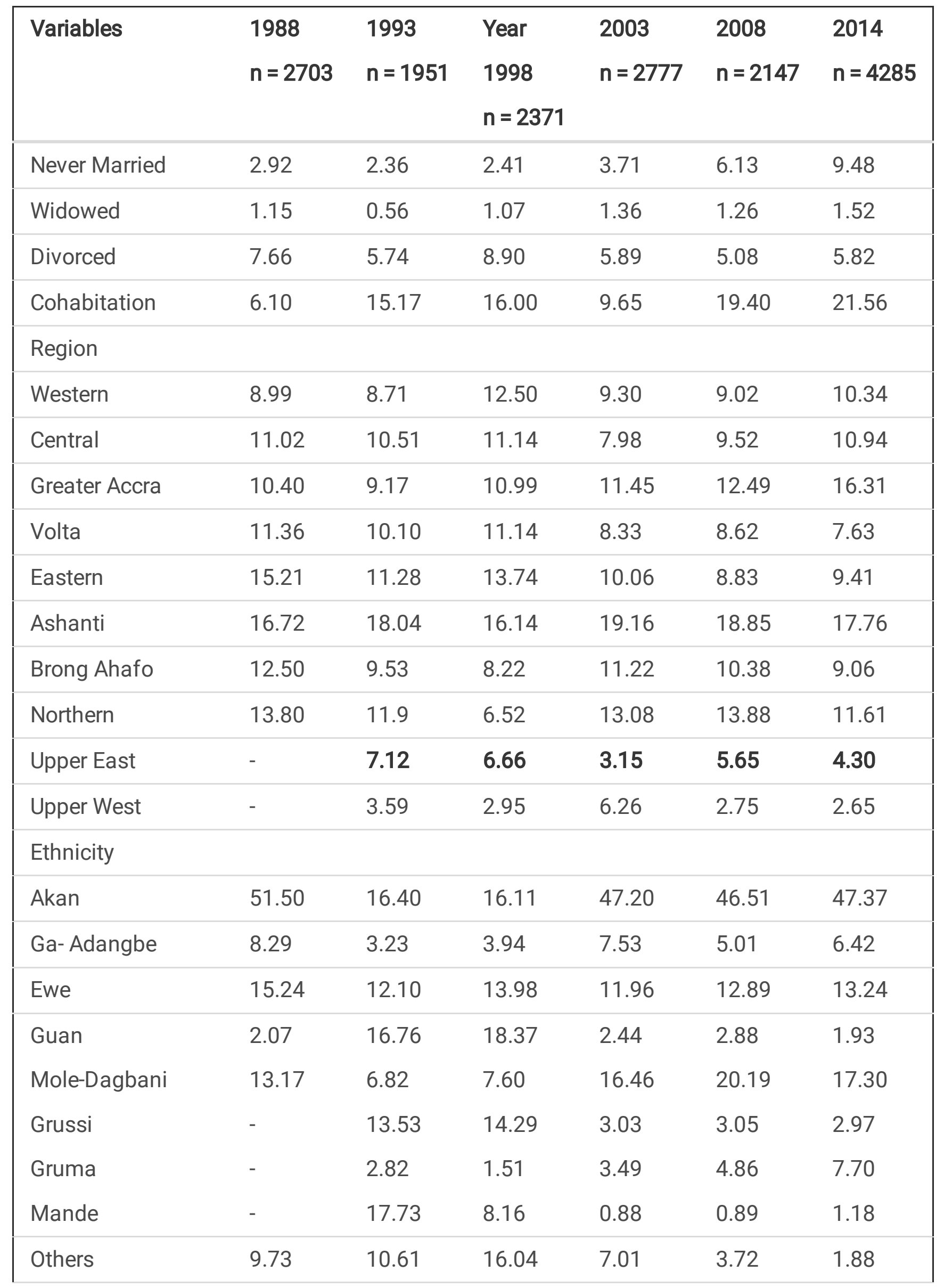

Source: Computed from GDHS 1988, 1993, 1998, 2003, 2008 and 2014 


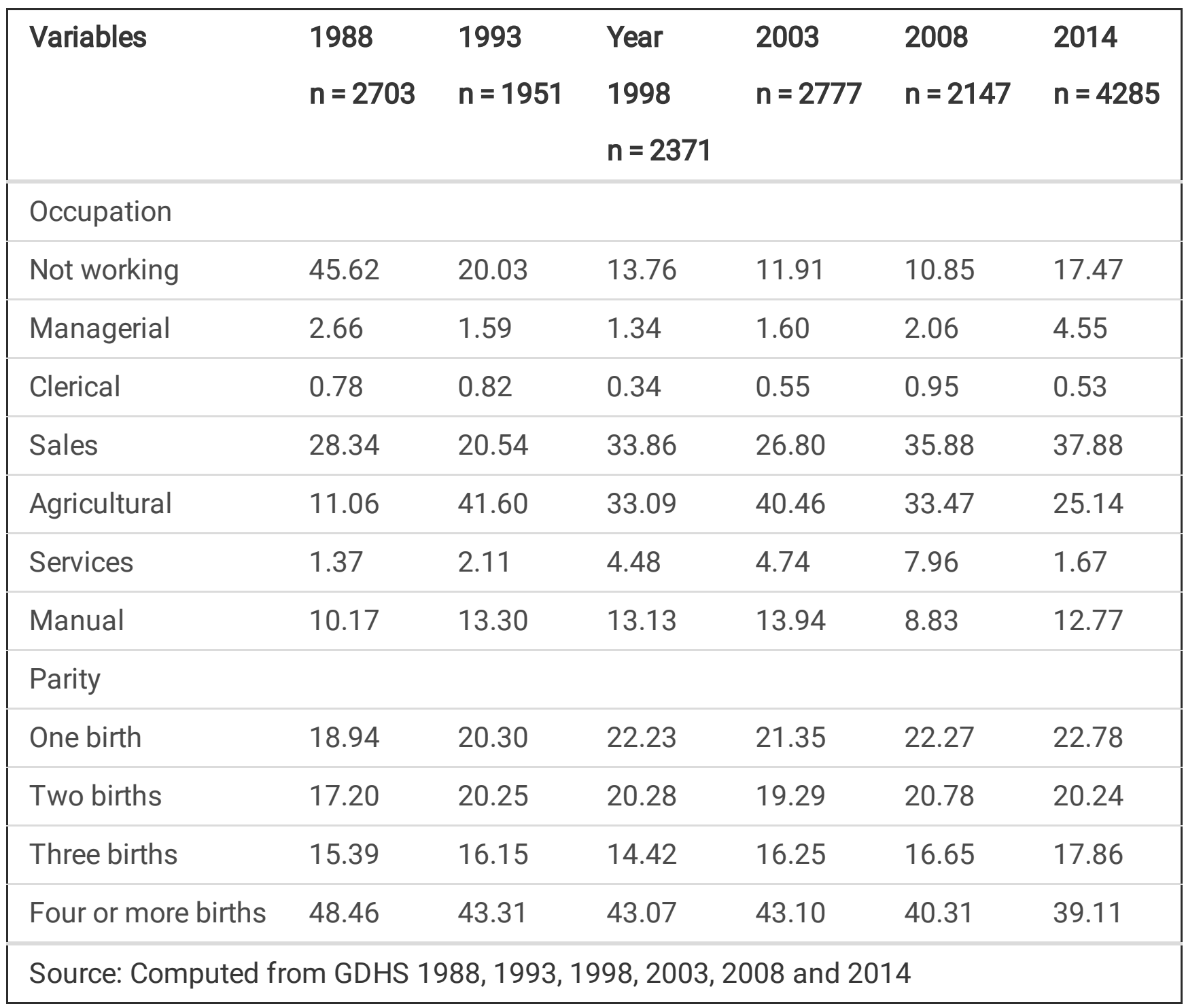

\section{Trends of Assisted Birth Delivery from 1988-2014}

The majority of the respondents over the years were assisted by nurses during birth delivery. The proportion of respondents assisted by nurses during birth delivery increased from about 35 percent in 1988 to about 66 percent in 2014 (see Fig. 1). The proportion of women who were assisted by traditional birth attendants during delivery reduced from about 28 percent in 1988 to about 15 percent in 2014 . Similarly, respondents who were not assisted by anyone during birth delivery were decreased by half from about 6 percent in 1988 to about 3 percent in 2014.

Logistic regression on assisted birth delivery

Women age $45-49$ years had a higher likelihood $(\mathrm{OR}=4.33, \mathrm{Cl}=2.05,9.15)$ of being assisted by a doctor during delivery compared to those age 15-19 years'. Also, women with secondary $(\mathrm{OR}=1.78, \mathrm{Cl}=1.34$, 2.37) and higher $(\mathrm{OR}=4.54, \mathrm{Cl}=2.44,8.46)$ education had a higher odd of being assisted by a doctor during delivery compared to those with no formal education (see Table 2). Women from rural areas (OR = $0.50, \mathrm{Cl}=0.40,0.63)$, who have had four or more births $(\mathrm{OR}=0.37, \mathrm{Cl}=0.27,0.52)$ and with having 
agriculture $(\mathrm{OR}=0.63, \mathrm{Cl}=0.45,0.88)$ as their occupation have a lesser likelihood of being assisted by a doctor during delivery compared to those from urban areas, with one birth and those who are not working respectively (see Table 2).

It was also observed that women age $35-39$ years $(\mathrm{OR}=2.26, \mathrm{Cl}=1.64,3.10)$, with secondary $(\mathrm{OR}=1.68$, $\mathrm{Cl}=1.44,1.96)$, higher $(\mathrm{OR}=4.54, \mathrm{Cl}=2.44,8.46)$ education and those with clerical $(\mathrm{OR}=2.44, \mathrm{Cl}=1.16$, 5.11) occupation had a higher odd of being assisted by a nurse during delivery compared to those aged 15-19 years, with no formal education and those who are not working (see Table 2). Also, women with richest wealth status were seen to have a higher likelihood $(\mathrm{OR}=1.72, \mathrm{Cl}=1.42,2.09)$ of being assisted by a nurse compared to those with poorest wealth status. The findings also showed that women from rural areas $(\mathrm{OR}=0.33, \mathrm{Cl}=0.29,0.38)$, with four and more births $(\mathrm{OR}=0.46, \mathrm{Cl}=0.37,0.56)$ and those from mole Dagbani ethic group $(\mathrm{OR}=0.68, \mathrm{Cl}=0.56,0.83)$ had a lesser odd of being assisted by a nurse compared to those from urban areas, with one birth and those from Akan ethnic group (see Table 2).

Findings from the study also showed that women aged 20-24 years $(\mathrm{OR}=0.64, \mathrm{Cl}=0.47,0.89)$, with higher education $(\mathrm{OR}=0.18, \mathrm{Cl}=0.04,0.78)$, and richest wealth status $(\mathrm{OR}=0.47, \mathrm{Cl}=0.37,0.06)$ had a lesser likelihood of utilizing the service of a traditional birth attendant during delivery compared to those aged 15-19 years, no formal education and those with poorest wealth status. Also women from the rural areas $(\mathrm{OR}=2.71, \mathrm{Cl}=2.26,3.26)$ had a higher odd of being assisted by a traditional birth attendant during delivery compared to those from the urban areas. Women with four or more births are more likely $(\mathrm{OR}=$ $1.30, \mathrm{Cl}=1.00,1.60)$ to utilize the services of a traditional birth attendants during delivery compare to who have one birth (see Table 2). 
Table 2

Logistic regression on assisted birth delivery

\begin{tabular}{|c|c|c|c|}
\hline \multirow[t]{2}{*}{ Variables } & Doctors & Nurses & TBA \\
\hline & $\begin{array}{l}\text { Odds Ratio (Confidence } \\
\text { interval) }\end{array}$ & $\begin{array}{l}\text { Odds Ratio (Confidence } \\
\text { interval) }\end{array}$ & $\begin{array}{l}\text { Odds Ratio (Confidence } \\
\text { interval) }\end{array}$ \\
\hline \multicolumn{4}{|l|}{ Age } \\
\hline $15-19$ & Ref & Ref & Ref \\
\hline $20-24$ & $1.38(0.85-2.24)$ & $1.26 *(0.98-1.63)$ & $0.90(0.67-1.20)$ \\
\hline $25-29$ & $1.19 * \star(1.16-3.15)$ & 1.62 ** $(1.23-2.14)$ & $0.64 * \star(0.47-0.89)$ \\
\hline $30-34$ & $2.64^{\star \star \star}(1.54-4.52)$ & $2.08^{\star \star \star}(1.54-2.81)$ & $0.58 * \star(0.41-0.83)$ \\
\hline $35-39$ & $3.66^{\star \star \star}(2.08-6.46)$ & 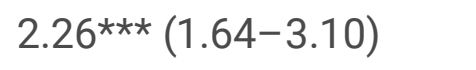 & $0.62 * \star(0.43-0.89)$ \\
\hline $40-44$ & $4.33^{\star \star \star}(2.34-8.01)$ & $2.13^{\star \star \star}(1.50-3.03)$ & $0.64 * \star(0.43-0.94)$ \\
\hline $45-49$ & $4.33^{\star \star \star}(2.05-9.15)$ & $2.08^{\star \star \star}(1.38-3.13)$ & $0.56 * *(0.36-0.87)$ \\
\hline \multicolumn{4}{|l|}{ Marital status } \\
\hline Never married & Ref & Ref & Ref \\
\hline Married & $1.06(0.68-1.65)$ & $0.88(0.66-1.18)$ & $1.50 *(1.00-2.25)$ \\
\hline Cohabitation & $0.78(0.49-1.25)$ & $0.85(0.63-1.15)$ & $1.31(0.86-2.00)$ \\
\hline Widowed & $0.54(0.17-1.69)$ & $0.97(0.55-1.72)$ & $1.26(0.63-2.51)$ \\
\hline Divorced & $0.96(0.56-1.63)$ & $0.60(0.51-1.00)$ & $1.76 * *(1.12-2.76)$ \\
\hline \multicolumn{4}{|l|}{ Education } \\
\hline No education & Ref & Ref & Ref \\
\hline Primary & $1.23(0.92-1.65)$ & $1.12(0.97-1.30)$ & $0.77^{\star *}(0.66-0.90)$ \\
\hline Secondary & $1.78^{\star \star \star}(1.34-2.37)$ & $1.68^{\star \star \star}(1.44-1.96)$ & $0.58 \star \star \star ~(0.48-0.70)$ \\
\hline Higher & $4.54^{\star \star \star}(2.44-8.46)$ & $1.90 * \star(1.10-3.28)$ & $0.18 * \star(0.04-0.79)$ \\
\hline \multicolumn{4}{|l|}{ Occupation } \\
\hline No occupation & Ref & Ref & Ref \\
\hline Managerial & $0.45^{\star *}(0.23-0.89)$ & $1.50 *(0.94-2.42)$ & $0.65(0.28-1.51)$ \\
\hline Clerical & $2.08^{* *}(1.07-4.05)$ & $2.44^{\star \star}(1.16-5.11)$ & $0.58(0.14-2.52)$ \\
\hline Sales & $1.11(0.84-1.45)$ & $1.37 \star \star \star(1.15-1.63)$ & $0.72 * *(0.58-0.89)$ \\
\hline
\end{tabular}

Ref $=$ Reference category ${ }^{*} p<0.05 * * p<0.01 * * * p<0.001$ 


\begin{tabular}{|c|c|c|c|}
\hline \multirow[t]{2}{*}{ Variables } & Doctors & Nurses & TBA \\
\hline & $\begin{array}{l}\text { Odds Ratio (Confidence } \\
\text { interval) }\end{array}$ & $\begin{array}{l}\text { Odds Ratio (Confidence } \\
\text { interval) }\end{array}$ & $\begin{array}{l}\text { Odds Ratio (Confidence } \\
\text { interval) }\end{array}$ \\
\hline Agricultural & $0.63^{* *}(0.45-0.88)$ & $0.80 * *(0.67-0.96)$ & $1.06(0.87-1.29)$ \\
\hline Services & $1.14(0.78-1.67)$ & $1.67 \star \star \star(1.28-2.16)$ & $0.60 * \star(0.41-0.89)$ \\
\hline Manual & $0.98(0.71-1.36)$ & $1.15(0.95-1.41)$ & $1.03(0.81-1.30)$ \\
\hline \multicolumn{4}{|l|}{ Ethnicity } \\
\hline Akan & Ref & Ref & Ref \\
\hline $\mathrm{Ga} /$ dangme & $1.19(0.83-1.70)$ & $0.88(0.68-1.12)$ & $0.82(0.60-1.11)$ \\
\hline Ewe & $1.03(0.77-1.38)$ & $0.71 \star \star \star(0.59-0.86)$ & $0.66^{\star \star \star}(0.53-0.83)$ \\
\hline Guan & $0.93(0.66-1.31)$ & $0.54 \star \star \star ~(0.44-0.65)$ & $0.30 \star \star \star ~(0.23-0.39)$ \\
\hline Mole Dagbani & $0.99(0.71-1.38)$ & $0.68^{\star \star \star}(0.56-0.83)$ & $0.63^{\star \star \star}(0.50-0.80)$ \\
\hline Grussi & $0.98(0.67-1.43)$ & $0.54 \star \star \star ~(0.43-0.67)$ & $0.61^{\star \star \star}(0.46-0.79)$ \\
\hline Gruma & $0.90(0.43-1.86)$ & $0.54^{\star \star}(0.38-0.76)$ & $0.76 *(0.56-1.03)$ \\
\hline Mande & $0.80(0.47-1.37)$ & $0.26^{\star \star \star}(0.20-0.35)$ & $1.24(0.94-0.63)$ \\
\hline Other & $0.95(0.32-2.80)$ & $0.45^{\star \star}(0.24-0.85)$ & $1.04(0.55-1.97)$ \\
\hline \multicolumn{4}{|l|}{ Region } \\
\hline Western & Ref & Ref & Ref \\
\hline Central & $0.92(0.59-1.43)$ & $0.70 * \star(0.55-0.89)$ & $1.30 * *(1.00-1.69)$ \\
\hline Greater Accra & $2.20 \star \star \star(1.53-3.16)$ & $1.07(0.84-1.36)$ & $0.76(0.53-1.09)$ \\
\hline Volta & $1.11(0.71-1.74)$ & $1.32^{\star \star}(1.02-1.70)$ & $0.97(0.72-1.31)$ \\
\hline Eastern & $0.88(0.58-1.33)$ & $0.95(0.75-1.19)$ & $1.21(0.93-1.58)$ \\
\hline Ashanti & $1.62 * *(1.14-2.31)$ & $1.21 *(0.98-1.49)$ & $0.57^{\star \star \star}(0.44-0.73)$ \\
\hline Brong Ahafo & $0.96(0.63-1.46)$ & $2.05^{\star \star \star}(1.63-2.58)$ & $0.69 * \star(0.53-0.91)$ \\
\hline Northern & $0.44 * \star(0.25-0.80)$ & $0.83(0.63-1.09)$ & $1.95^{\star \star \star}(1.49-2.57)$ \\
\hline Upper East & $0.37^{\star \star}(0.17-0.81)$ & $1.88^{\star \star \star}(1.38-2.56)$ & $0.72 \star \star(0.51-1.00)$ \\
\hline Upper West & $0.75(0.41-1.38)$ & $1.62^{\star \star}(1.20-2.19)$ & $0.53^{\star \star \star}(0.38-0.73)$ \\
\hline
\end{tabular}

Ref $=$ Reference category ${ }^{*} p<0.05 * * p<0.01 * \star * p<0.001$ 


\begin{tabular}{|c|c|c|c|}
\hline \multirow[t]{2}{*}{ Variables } & Doctors & Nurses & TBA \\
\hline & $\begin{array}{l}\text { Odds Ratio (Confidence } \\
\text { interval) }\end{array}$ & $\begin{array}{l}\text { Odds Ratio (Confidence } \\
\text { interval) }\end{array}$ & $\begin{array}{l}\text { Odds Ratio (Confidence } \\
\text { interval) }\end{array}$ \\
\hline Poorest & Ref & Ref & Ref \\
\hline Poorer & $0.99(0.71-1.39)$ & $1.23^{\star \star}(1.04-1.45)$ & $0.87(0.74-1.03)$ \\
\hline Middle & $0.95(0.68-1.33)$ & $1.43^{\star \star \star}(1.21-1.70)$ & $0.83^{* \star}(0.69-0.99)$ \\
\hline Richer & $1.02(0.74-1.43)$ & 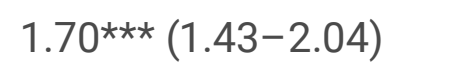 & $0.69 * \star \star(0.56-0.84)$ \\
\hline Richest & $1.18(0.84-1.66)$ & $1.72^{\star \star \star}(1.42-2.09)$ & $0.47 \star \star \star(0.37-0.60)$ \\
\hline \multicolumn{4}{|l|}{ Residence } \\
\hline Urban & Ref & Ref & Ref \\
\hline Rural & $0.50 \star \star \star ~(0.40-0.63)$ & $0.33^{\star \star \star}(0.29-0.38)$ & 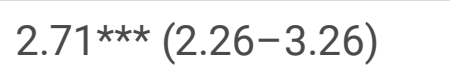 \\
\hline \multicolumn{4}{|l|}{ Parity } \\
\hline One birth & Ref & Ref & Ref \\
\hline Two births & $0.65^{\star \star}(0.51-0.85)$ & $0.64 \star \star \star(0.54-0.76)$ & $1.15(0.93-1.42)$ \\
\hline Three births & $0.47 \star \star \star(0.34-0.64)$ & $0.54 \star \star \star ~(0.44-0.66)$ & 1.36 ** $(1.07-1.73)$ \\
\hline $\begin{array}{l}\text { Four or more } \\
\text { births }\end{array}$ & $0.37^{\star \star \star}(0.27-0.52)$ & $0.46^{\star \star \star}(0.37-0.56)$ & $1.30 * \star(1.00-1.66)$ \\
\hline Pseudo $\mathrm{R}^{2}$ & 0.1508 & 0.1730 & 0.1192 \\
\hline Prob $>X^{2}$ & 0.0000 & 0.0000 & 0.0000 \\
\hline
\end{tabular}

\section{Discussion}

The paper sought to examine the predictors of assisted birth delivery. Results showed that majority of the respondents over the years were assisted by nurses/midwives during birth delivery. The proportion of births assisted by nurses during child delivery increased over the years. Similar result was found in Garu Tempane District of Ghana where there was increase in the proportion of women who utilized the service of a skilled attendants such as nurses during birth delivery [19]. Hossain et al., (2020) also confirmed this in his study at Bangladesh. The study concluded that women receiving assistance from nurses increased from 69 percent in 1994 to 73 percent in 1999 [20]. 
Again, [21] posited similar findings in their study. The study concluded that women receiving care from skilled attendants have had an upward trend over the years, increasing from about 25 percent in 1996 to about 58 percent in 2011. There was a reduction in the proportion of birth assisted by Traditional Birth Attendants over the years (see Fig. 1). This finding goes contrary to the finding of [22]. They found out that more than half of the births occurred in the home with the assistance of TBAs. This might be as a result of the distance to the health facility or the cost of delivering in a health facility. The increased in the proportion of birth assisted by nurses can be as a result of the introduction of the CHPS compound in the country. This brought health services to the doorsteps of the citizenry, especially, those in the rural areas.

This section sought to examine the proportion of delivery that was assisted by doctors from 1988 to 2014. It was observed that the proportion had increased in 2014. This confirms the study by [23], that there has been an increase in birth delivery assisted by doctors in developing regions. Similarly, [24] posited that utilization of skilled birth attendants such as doctors was low from 1988 but increased sharply and levelled off after 2003. However, [25] in their cross-sectional study conducted among women who had ever given birth in the three years prior to the study concluded about 79 percent of respondents were assisted by skilled attendants such as doctors. This might be as a result of the introduction of the free maternal health care policy in the country.

The result also shows that older women were four times more likely to utilize the services of doctors compared with younger women. Similar results were found by the work conducted [7]. He concluded that younger women do not utilize the services of doctors because they do not have power in decision making in their homes even though it affects their own health. $[26,27]$ gave different opinion in their study conducted in rural Tanzania that younger mothers utilized the services of doctors during birth delivery [27]. This might be because of the fear of dying from pregnancy if not attended to by a skilled worker. This result is in line with the Conceptual framework that, the predisposing factors such as age has an association with delivery assisted by doctors [28]. Women working in the clerical sector were twice more likely to utilize the services of doctors during delivery compared with those not working. This is consistent with the study conducted at Bangladesh by [29] which found that women who worked for cash went to qualified medical personnel such as doctors for assistance during birth delivery. [17] in their cross sectional descriptive study at Ga East Municipality came out with similar findings.

It shows clearly that respondents with higher education were four times more likely to be assisted by doctors during birth delivery compared with those with no education $(O R=4.54, p<0.001)$. A cross sectional study conducted at Makueini, Kenya concluded that mothers with higher education were assisted by skilled attendants such as doctors during birth delivery [30]. Also, study conducted at Bangladesh posited that the odds of utilizing the services of skilled attendants such as doctors increased with mother's education [31]. Mpembeni et al., (2007) in a study conducted at Southern Tanzania concluded that years spent in school showed a significant association with seeking skilled care such as doctors during birth delivery [32]. Women with more schooling years had the highest proportion of deliveries attended by doctors. 
Women with a child or less were more likely to utilize the services of doctors during birth delivery. Chakraborty et al. (2003) posited similar finding that the percentage of women who sought care from a doctor decreased from 29 percent in women with no pregnancies to about 26 percent in mothers with one to four births [29]. Also, [33] affirm that Skilled Delivery Attendance was higher among women who were primigravida. Respondents from the rural areas were less likely to utilize the services of doctors during birth delivery. This confirms the study conducted in Ghana from 1988-2008 by [24]. They concluded that there is a percentage gap between women in the rural and urban areas in accessing the services of skilled attendants such as doctors during delivery.

This section sought to analyze birth delivery assisted by nurses/midwives from 1988 to 2014 . The results show that proportion of birth delivery assisted by nurses/midwives has increased over the years. This confirms the cross-sectional study by [25], that among women who had ever given birth, the proportion of birth assisted by nurses/midwives had increased to about 79 percent. Also, the study by [34] conducted at Kenya confirms this finding. On the other hand, [24] concluded that the proportion of birth assisted by skilled birth attendants such as nurses/midwives has been low. This they attribute to the attitude of nurses/midwives towards patients at the facility.

It was also realized that older women were two times more likely to utilize the services of nurses/midwives compared with younger women during birth delivery. This is in line with the study by conducted by [7]. He concluded that younger women do not utilize the services of nurses/midwives because they do not have power in decision making in their homes even though it affects their own health. Also, a bivariate analysis suggested that older women were more likely to utilize maternal healthcare services than younger women [29]. Contrary to this, [35] concluded that younger women utilized the services of skilled attendants such as nurses/midwives because they are just starting child bearing and they are in a high risk so they tend to fear delivering without assistance.

Compared with women in the Western Region, women from the Greater Accra Region were more likely to utilize the services of nurses/midwives during birth delivery. In a study conducted at Nigeria confirms that Region was statistically significant factor that affected the use of skilled delivery [36]. A study by [37] posited different finding when they concluded that Region was not found to predict skilled attendance during delivery in their study in Ghana Using the 2008 Ghana Demographic and Health Survey. With reference to the occupation of the respondents, it was clear that women working in the clerical sector were two times more likely to utilize the services of nurses/midwives compared with those not working. This confirms the study by [17] conducted at Ga East Municipality in Ghana that maternal occupation showed statistical association with the assisted delivery. Also, [38] in their study at Nigeria concluded that women who were working in a modern-sector occupation had 3.66 odds of receiving assistance from skilled attendants such as nurses/midwives during birth delivery.

The findings show that women with higher education were twice more likely to utilize the services of nurses/midwives compared with those with no education. A study conducted at Southern Tanzania concluded that years spent in school showed a significant association with seeking skilled care such as 
doctors during delivery [32]. Women with more schooling years had the highest proportion of deliveries attended by doctors. [31] concluded in multivariate regression that the odds of being assisted by nurses/midwives during delivery increased with mother's education. Also, a study in Kenya [34], Sierra Leon, Niger and Mali [12] and Ghana [13] established that women with higher education were more likely to use skilled attendant such as nurses/midwives.

Finally, this section sought to assess birth delivery assisted by traditional birth attendants from 1988 to 2014. According to [39], unskilled birth attendants are also called traditional birth attendants which is a community-based provider of care during pregnancy and childbirth. In general, there has been a decline in birth assisted by traditional birth attendants in Ghana. This is contrary to the report from the Nepal Demographic Health Survey which reported that about 81 percent of deliveries are assisted by unskilled birth attendants. Also, a report by [40] also concluded that most women prefer to have a Traditional birth attendant at delivery because they perceived pregnancy and child birth as a natural phenomenon and does not require formal health services. Again, a study conducted in Talensi District of Ghana by [41] among women, TBAs and key informants stated majority of women were persisting in utilizing unskilled birth attendants largely because they believe services provided by unskilled birth attendants are good for them. The high usage of Traditional birth attendants during birth delivery will be as a result of ignorance, availability of TBAs and poor access to skilled services [41, 42].

It is evident that women from the Northern region were twice more likely to utilize the services of TBAs during birth delivery compared with those in the Western region. This is in line with the study by [25] conducted at Northern part of Ghana. The study concluded that respondents from these places were more likely to utilize the services of Traditional birth attendants during birth delivery. In a study conducted to identify demographic, maternal and community predictors of skilled attendance at delivery among women, region was found to be associated with delivery assisted by traditional birth attendants [37].

Women who work in the agricultural sector are more likely to utilize the services of traditional birth attendants during delivery compared with those not working. This contradicts the study by [17] conducted at Ga East Municipality in Ghana that maternal occupation showed statistical association with the utilization of assisted delivery. Also, in a study at Nigeria concluded that women who were working in a modern-sector occupation had 3.66 odds of receiving assistance from skilled attendants such as nurses/midwives during birth delivery [38].

Some studies seem to suggest that rural women utilize the services of traditional birth attendants during birth delivery $[24,33]$. Consistent with these previous studies, the result shows that women from the rural areas were thrice more likely to utilize the services of traditional birth attendants during birth delivery compared with women from the urban areas. Women with no education were more likely to utilize the services of traditional birth attendants during delivery compared with those with higher education. This confirms the work of [31], that women with little or no education were more likely to utilize the services of TBAs during birth delivery. Also, a study at Kenya concluded that women with no education were more likely to use traditional birth attendants during birth delivery [30]. 


\section{Conclusion}

Level of education, ethnicity, place of residence, parity, age, marital status and occupation a significant association with the choice of attendant during delivery. These findings heighten that future successful interventions for skilled birth attendants should prioritise the identified groups who were more likely to utilize the services of TBAs.

\section{Abbreviations}

GDHS: Ghana Demographic and Health Survey; TBA: Traditional Birth Attendant; CHPS: Communitybased Health Planning and Services (CHPS) Program; CHO: Community Health Officers WHO: World Health Organization; SSA: Sub-Saharan Africa; UNICEF: United Nations International Children's Emergency Fund

\section{Declarations}

\section{Acknowledgements}

We are grateful to MEASURE DHS and for granting us access to use the data

\section{Authors' contribution}

KFO, RAM, and KSD conceptualized the study. KFO conducted the statistical analysis. KSD drafted the manuscript. KFO, RAM and KSD reviewed and approved the final manuscript

\section{Funding}

None

\section{Availability of data and materials}

The dataset is available openly at https://dhsprogram.com/data/available-dataset.cfm.

\section{Ethics approval}

Not required (The study used secondary data which had already received ethical clearance).

\section{Consent for publication}

Not required

\section{References}

1. Ghana Statistical Service (GSS), Ghana Health Service (GHS), and ICF International (2015). Ghana Demographic and Health Survey 2014. Rockville, Maryland, USA: GSS, GHS, and ICF International. 
2. United Nations. (2015). General Assembly: Summit for the adoption of the post - 2015 development United Nations Development Programme Ghana and NDPC/GOG (2015). 2015 Ghana Millennium Development Goals Report. Accra: Republic of Ghana.

3. Fitzpatrick, K. E., Gray, R., \& Quigley, M. A. (2016). Women's longitudinal patterns of smoking during the pre-conception, pregnancy and postnatal period: evidence from the UK infant feeding survey. PLoS One, 11(4), e0153447

4. Dahiru, T., \& Oche, M. O. (2015). Determinants of antenatal care, institutional delivery and postnatal care services utilization in Nigeria. Pan African Medical Journal, 21, 1-17. doi.org/10.11604/pamj.2015.21.321.6527.

5. Gordon, O. (2019). The First Breath: How Modern Medicine Saves the Most Fragile Lives. Boxtree.

6. Garces, A., McClure, E. M., Espinoza, L., Saleem, S., Figueroa, L., Bucher, S., \& Goldenberg, R. L. (2019, August). Traditional birth attendants and birth outcomes in low-middle income countries: A review. In Seminars in perinatology(Vol. 43, No. 5, pp. 247-251). WB Saunders.

7. Crain, C. (2019). Exploring the Female Perspective: Culturally Sensitive Models for the Effective Use of Traditional Birth Attendants in Rural Tanzania.

8. Ohaja, M., Murphy-Lawless, J., \& Dunlea, M. (2020). Midwives' views of traditional birth attendants within formal healthcare in Nigeria. Women and Birth, 33(2), e111-e116.

9. Olaore, A. Y., Ezeokoli, N. R., \& Ogunlade, V. B. (2020). Community Traditional Birth Attendants and Cultural Birthing Practices in Nigeria: Social Work Implications. Community Practice and Social Development in Social Work, 1-20.

10. Victoria, K. M., Patricia, M. K., Mutinta, M., Concepta, K., Emmanuel, M., Fabian, C., . \& Margaret, M. C. (2020). Midwives perspectives on risk factors influencing maternal morbidity and mortality rates in Zambia: A case of Lusaka and Mumbwa Districts. International Journal of Nursing and Midwifery, 12(2), 64-70.

11. Choguya, N. Z. (2014). Traditional Birth Attendants and Policy Ambivalence in Zimbabwe. Journal Of Anthropology, 2014: 1 - 9 dx.doi.prg/10.1155/2014/750240.

12. Ameyaw, E. K., \& Dickson, K. S. (2020). Skilled birth attendance in Sierra Leone, Niger, and Mali: analysis of demographic and health surveys. BMC Public Health, 20(1), 164.

13. Amu, H., Dickson KS. (2018). Effects of Spatial Location and Household Wealth on the Utilisation of Skilled Birth Attendants at Delivery Among Women in Rural Ghana. Ghana Journal of Geography, 10(1), 58-77.

14. World Health Organisation. (2014). World Health Statistics. Geneva: World Health

15. Amissah, J., Nakua, E. K., Badu, E., Amissah, A. B., \& Lariba, L. (2020). In search of universal health coverage: the hidden cost of family planning to women in Ghana. BMC research notes, 13(1), 58.

16. Nyonator, F. K., Awoonor-Williams, J. K., Phillips, J. F., Jones, T. C., \& Miller, A. (2005). The Ghana community-based health planning and services initiative for scaling up service delivery innovation. Health Policy Plan. 20: 25-34. 
17. Esena, R. K., \& Sappor, M. M. (2013). Factors associated with the utilization of skilled delivery services in the Ga East Municipality of Ghana Part 2: barriers to skilled delivery. Int J Sci Tech Res, 2(8), 195-207.

18. Atinga, R., Baku, A., \& Adongo, P. (2014). Drivers of prenatal care quality and uptake of supervised delivery services in Ghana. Annals of Medical and Health Sciences Research, 4(9), 264.

19. Ganle, J. K., Kombet, M. L., \& Baatiema, L. (2019). Factors influencing the use of supervised delivery services in Garu-Tempane District, Ghana. BMC pregnancy and childbirth, 19(1), 141.

20. Hossain, J., Laterra, A., Paul, R. R., Islam, A., Ahmmed, F., \& Sarker, B. K. (2020). Filling the human resource gap through public-private partnership: Can private, community-based skilled birth attendants improve maternal health service utilization and health outcomes in a remote region of Bangladesh? PloS one, 15(1), e0226923.

21. Shrestha, S., Bell, J. S., \& Marais, D. (2014). An Analysis of Factors Linked to the Decline in South Asia will not be attended by a skilled birth attendant between 2011 and 2015? BMC Pregnancy and Childbirth 12:4.

22. Tey, N., \& Lai, S. (2013). Correlates of and barriers to the utilization of Health Services for delivery in South Asia and Sub Saharan Africa. The Scientific World Journal. 2013 (11). doi:10.1155/2013/423403.

23. Garshong, B., Ansah, E., Dakpallah, G., Huijts, I., \& Adjei, S. (2002). A study on factors affecting the implementation of the exemption policy in Ghana. Bulletin of Health Information. 1:22-31.

24. Asamoah, B. O., Agardh, A., Pettersson, K. O., \& Östergren, P. O. (2014). Magnitude and trends of inequalities in antenatal care and delivery under skilled care among different socio-demographic groups in Ghana from 1988-2008. BMC pregnancy and childbirth, 14(1), 295-319.

25. Sakeah, E., McCloskey, L., Bernstein, J., Yeboah-Antwi, K., Mills, S., and Doctor, H.V. (2014). Is there any role for community involvement in the community-based health planning and services skilled delivery program in rural Ghana? BMC Health Services Research, doi: 10.1186/1472-6963- 14340 .

26. Kayombo, E. J. (2013). The impact of Training traditional birth attendants on maternal mortality and morbidity in Sub-Saharan African countries. Tanzania Journal of Health Research, 15 (2), doi:10.4314/thrb. v15i2.7.

27. Mrisho, M., Schellenberg, J. A., Mushi, A. K., Obrist, B., Mshinda, H., Tanner, , \& Schellenberg, D. (2007). Factors affecting home delivery in rural Tanzania. Tropical Medicine \& International Health, 12(7), 862-872.

28. Anderson, E. A. (1995). Measuring service quality at a university health clinic. International journal of health care quality assurance.

29. Chakraborty, N., Islam, M. A., Chowdhury, R. I., Bari, W., \& Akhter, H. H. (2003). Determinants of the use of maternal health services in rural Health promotion international, 18(4), 327-337.

30. Gitimu, A., Herr, C., Oruko, H., Karijo, E., Gichuki, R., Ofware, P., ... \& Nyagero, J. (2015). Determinants of use of skilled birth attendant at delivery in Makueni, Kenya: a cross sectional study. BMC 
pregnancy and childbirth, 15(1), 9.

31. Do, N., Tran, H. T. G., Phonvisay, A., \& Oh, J. (2018). Trends of socioeconomic inequality in using maternal health care services in Lao People's Democratic Republic from year 2000 to 2012. BMC Public Health, 18(1), 875.

32. Mpembeni, R. N., Killewo, J. Z., Leshabari, M. T., Massawe, S. N., Jahn, A., Mushi, D., \& Mwakipa, H. (2007). Use pattern of maternal health services and determinants of skilled care during delivery in Southern Tanzania: implications for achievement of MDG-5 targets. BMC pregnancy and childbirth, 7(1), 29.

33. Lund, S., Hemed, M., Nielsen, B. B., Said, A., Said, K., Makungu, M. H., \& Rasch, V. (2012). Mobile phones as a health communication tool to improve skilled attendance at delivery in Zanzibar: a cluster-randomised controlled trial. BJOG: An International Journal of Obstetrics \& Gynaecology, 119(10), 1256-1264.

34. Shikuku, D. N., Mukosa, R., Peru, T., Yaite, A., Ambuchi, J., \& Sisimwo, K. (2019). Reducing intrapartum fetal deaths through low-dose high frequency clinical mentorship in a rural hospital in Western Kenya: a quasi-experimental study. BMC Pregnancy and Childbirth, 19(1), 518.

35. Thind, A., Mohani, A., Banerjee, K., \& Hagigi, F. (2008). Where to deliver? Analysis of choice of delivery location from a national survey in India. BMC Public Health, 8(1), 29.//doi.org/10.1186/1471-2458-829.

36. Okonofua, F., Ntoimo, L., Ogungbangbe, J., Anjorin, S., Imongan, W., \& Yaya, S. (2018). Predictors of women's utilization of primary health care for skilled pregnancy care in rural Nigeria. BMC pregnancy and childbirth, 18(1), 1-15.

37. Dotse-Gborgbortsi, W., Tatem, A. J., Alegana, V., Utazi, C. E., Ruktanonchai, C. W., \& Wright, J. (2020). Spatial inequalities in skilled attendance at birth in Ghana: a multilevel analysis integrating health facility databases with household survey data. Tropical Medicine \& International Health, 25(9), 10441054.

38. Alex-Ojei, C. A., Odimegwu, C. O., \& Akinyemi, J. O. (2020). Patterns of delivery assistance among adolescent mothers in Nigeria. Midwifery, 82, 102619.

39. Mcnojia, S. Z., Saleem, S., Feroz, A., Khan, K. S., Naqvi, F., Tikmani, S. S.,. \& Goldenberg, R. L. (2020). Exploring women and traditional birth attendants' perceptions and experiences of stillbirths in district Thatta, Sindh, Pakistan: a qualitative study. Reproductive Health, 17(1), 1-11.

40. (2012). The state of the world's children 2012: children in an urban world. eSocialSciences

41. Dapaah, J. M., \& Nachinaab, J. O. (2019). Sociocultural determinants of the utilization of maternal health care services in the Tallensi District in the Upper East Region of Ghana. Advances in Public Health, 2019.

42. Aziato, L., \& Omenyo, C. N. (2018). Initiation of traditional birth attendants and their traditional and spiritual practices during pregnancy and childbirth in Ghana. BMC pregnancy and childbirth, 18(1), 64. 
Figures

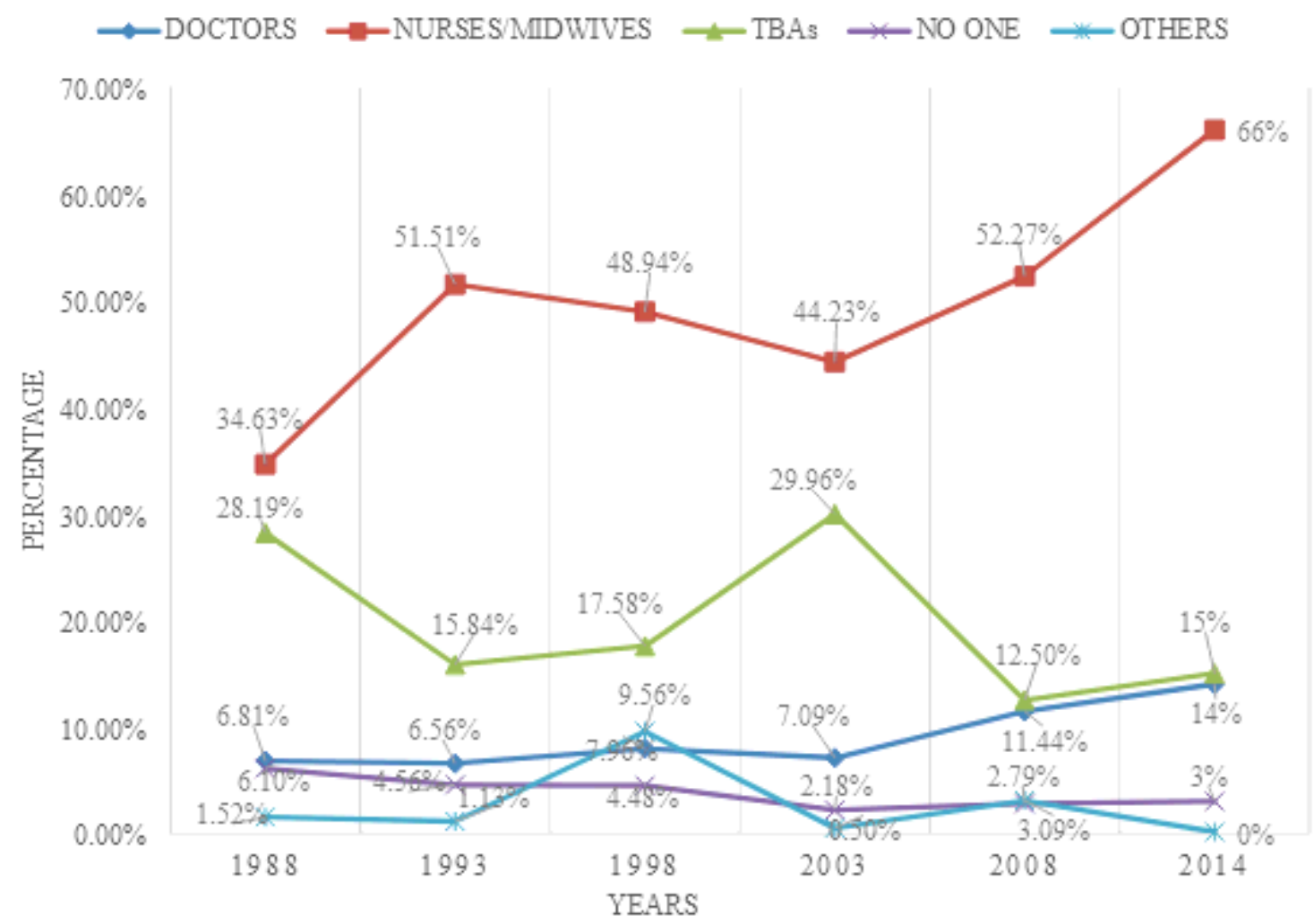

\section{Figure 1}

Trends of Assisted Birth Delivery from 1988-2014. Source: Computed from GDHS 1988, 1993, 1998, 3003, 2008 and 2014. 